\title{
ENSAYOS
}




\section{TRANSICION ESTRUCTURA Y EDUCACION: LA SITUACION DE LA JUVENTUD*}

Germán W. Rama**

\section{Aspiraciones educativas y cambios de la sociedad}

Entre las diversas transformaciones que señalan el proceso de transición en América Latina la educación es la que tiene registro más elevado y entre las diversas demandas sociales la educación constituye el punto de acuerdo de las aspiraciones de los distintos grupos sociales.

Sin desmedro de los esfuerzos de planificación de los gobiernos de la región el avance educativo es por encima de todo el resultado de la movilización social en el sentido de que los diversos grupos sociales —en diversos tiempos - han expresado aspiraciones muy vigorosas que de una u otra forma fueron aceptadas y canalizadas por los gobiernos. La aspiración social es tan vigorosa que aun aquellos que intentaron resistir esa demanda ya sea por razones económicas o políticas, no lograron contenerlas.

Cuando se compara la evolución educativa de la región con la de países europeos el fenómeno más llamativo es que mientras en los segundos las aspiraciones educativas de la sociedad se limitaron a seguir los requerimientos del mercado en cuanto a requerimientos educativos de la mano de obra y cada grupo social aspiró a obtener la educación correspondiente a su nivel estratificado en la sociedad, en América Latina en tomo a la educación se registra una revolución de las expectativas. La sociedad valora en tan alto grado la educación que la demanda por encima de los requerimientos que tiene el mercado de empleo para reclutar a la fuerza de trabajo y las aspiraciones no tienen correlación con la posición social de la familia. Mientras en materia de vivienda o de ingresos como por ejemplo, los grupos populares urbanos se satisfacen con niveles limitados, en materia de educación las aspiraciones son infinitas. En modestas familias, con precarias viviendas y condiciones de trabajo, los padres analfabetos y con incipiente educación primaria aspiran a que sus hijos realicen estudios universitarios. La aspiración aparentemente es insostenible si se considera que en esos hogares no existe un capital cultural ni instrumentos de formación, tales como libros, y que requerirán del esfuerzo económico desde temprana edad de esos hijos en relación con los cuales confían en un porvenir culturalmente tan elevado. Esta discrepancia es interpretada habitualmente como una manifestación de desajuste entre condición social y aspiraciones. Sin embargo, detrás de ella figuran los elementos más importantes en la construcción de un estilo de desarrollo alternativo de las sociedades latinoamericanas.

Ellos son fundamentalmente de tres tipos: la aspiración a la movilidad social, la jerarquía de la dimensión cultural y el ansia de integración nacional. El discurso político desde la declaración de independencia en adelante afirmó que las sociedades del Nuevo Mundo se constituían como sociedades diferentes en las que la igualdad era la norma y en la que el status de los individuos provenía de sus méritos y virtudes. Este discurso -a pesar que la realidad indicaba lo contrario- fue reiterado como fundamento de la legitimidad del sistema político y fue asimilado por la sociedad que creyó y cree que es el válido, por lo que la educación fue considerada la forma de hacer realidad dicho discurso. Esto por una parte explica la transferencia a su propia responsabilidad que los individuos

\footnotetext{
* Ponencia presentada en el seminario CLACSO sobre Educación, Sao Paulo, junio de 1983.

** Director de la División de Desarrollo Social de CEPAL.
} 
realizan para explicar sus escasos logros sociales; así es frecuente que en las encuestas en América Latina los entrevistados expliquen su poco éxito social sobre la base de su baja educación y no por discriminaciones de que hubieran sido objetos como consecuencia de una injusta distribución del poder social. Pero el reverso de esta autoinculpación es la demanda de servicios educativos para poder hacer realidad el discurso político fundacional. Como por otra parte en el mercado de trabajo y en el reconocimiento de status se adjudicó un alto valor al capital educativo -lo que se mide por la alta diferencia de ingresos entre educados y no educados y la reserva de posiciones sociales prestigiosas para quienes tienen altos niveles educativos -el contenido democrático de la demanda educativa encontró apoyo en esas gratificaciones económicas y de status cuyo valor fue creciendo en la medida en que el consumo y el bienestar material fue jerarquizado socialmente con la difusión de las pautas de la sociedad capitalista.

El segundo elemento es el de la jerarquía de la dimensión cultural. En las sociedades europeas la cultura estuvo asociada a la condición de un grupo social superior y la cultura constituía una distinción del grupo que era transmitida por la vía familiar, lo que entre otras cosas se manifestaba en la importancia que revestían las diferentes formas de hablar como manifestación del origen social de los individuos. En América Latina el largo ciclo de conflictos por la constitución del Estado y la sucesión de cambios económicos con consiguiente renovación parcial o total de grupos superiores impidieron la constitución de una cultura superior transmitida por vías familiares. Por el contrario, la cultura era una creación del sistema educativo y por tanto teóricamente accesible a todos. Educarse era la forma de adquirir una nueva dimensión de la persona que resultaba tanto o más prestigiosa que la acumulación de bienes. Esto último, que fuera interpretado negativamente como contrario a los valores del desarrollo económico y que por algunos autores fuera explicado como efecto de una transmisión de modelos caballerescos de la colonia Luso-española, debe ser reinterpretado como un valor que se adelanta o que contiene en ciernes lo que constituirá un factor clave de las sociedades postmodernas.

El tercer elemento es el de la integración nacional. En las sociedades originarias de inmigración internacional y las mayoritarias provenientes de la fusión de aportes multirraciales agregados arbitrariamente en relaciones de dependencia personalizada, la aspiración a constituir la nación se encuentra una y otra vez bloqueada por las tendencias exclusivistas de los grupos que detentaron el poder. En los regímenes oligárquicos el pueblo fue descalificado para intervenir en la cosa pública en virtud de su ignorancia y ésta se mantenía por la ausencia de oferta educativa; posteriormente en el discurso restrictivo de burocracias políticas o de grupos tcenocráticos se afirmó que la complejidad de los problemas a resolver sólo habilitaba a unos pocos para adoptar decisiones, es decir que en uno y otro caso la falta de educación fue presentada como la razón formal de la exclusión en una sociedad nacional y por ende participativa. Educación queda asociada a ciudadanía y en algunas sociedades latinoamericanas el analfabetismo fue excluyente de la condición de elector hasta la década pasada. Pero más allá de las restricciones legales a la condición de ciudadano la educación fue percibida como la vía por excelencia para poder participar en la sociedad política, es decir en la sociedad nacional.

Este conjunto de factores explica que la generación joven tenga hoy registros de niveles educacionales que la hacen cualitativamente distinta de la generación adulta. En las últimas tres décadas se produjeron cambios en la educación que se manifiestan en los grupos jóvenes a través de los rasgos que se indican a continuación. 
El primero de ellos es el del analfabetismo. Este era predominante entre los adultos (aproximadamente la mitad de la población de más de 15 años de edad se declaraba en los censos de los años 50 como analfabetas) y en un conjunto de países es ya residual entre los jóvenes; en otro conjunto de países decrece pronunciadamente en cada período intercensal lo que permite suponer que será residual hacia fines del siglo y por último en los países de mayor población rural, en aquellos otros que tienen aún una importante masa indígena y por último en el país de mayor volumen población de la región continúa registrando guarismos de más del $15 \%$, con la característica de que ese analfabetismo implica hacia fines del presente siglo una discriminación social más importante que lo que era en el pasado.

El segundo rasgo es el del acceso de la casi totalidad de los niños a la escuela primaria. El incremento de la oferta ha permitido que los potenciales educandos accedan a los establecimientos escolares pero aún sólo alrededor de la mitad de los mismos, para el conjunto de la región, logra finalizar un ciclo de escolarización promedio de 6 años de educación. Esto se proyecta para la actual generación joven y para las futuras en un grave desequilibrio cultural y social puesto que la condición del desarrollo económico, social y político es el de que toda la población participe de un mínimo y compartido código cultural.

El tercer rasgo es el de la transformación de la educación media, que en el pasado era una formación elitaria para quienes estaban destinados a los estudios universitarios y a la que se encontraba adosada una formación manual de fuerte contenido empírico -a la que se destinaban los grupos sociales urbanos pero de nivel social bajo- en una educación progresivamente integrada en torno a la formación cultural general que comprende con excepción de 4 países, entre un 15\% y un $60 \%$ del grupo de edad de 13 a 19 años.

El cuarto rasgo es el de la velocísima transformación cuantitativa de la educación superior. Hacia 1950, ésta comprendía poco más del 10/o de los jóvenes de 20 a 24 años mientras hoy incorpora a más del $16 \%$ y salvo Haití, Guatemala y Honduras, en todos los países por lo menos uno de cada diez jóvenes asiste a la universidad. Estos cambios cuantitativos recubren una transformación cualitativa ya que los niveles elitarios por excelencia se han transformado en niveles masivos para la población joven lo que debe ser analizado como un potencial de recursos humanos, de capacidad cultural y de virtualidad política para la transformación de América Latina.

Esta evolución educativa ha tenido características desiguales, según los países, que se reflejan en los niveles educacionales de los jóvenes que luego se analizarán en detalle. Un primer conjunto de países corresponde a aquellos de temprana modernización educativa que han logrado una escolarización primaria casi total y un desarrollo congruente de sus niveles medio y superior. El segundo, es el de los países que en breves años realizaron una especie de "mutación" de sus niveles educativos con la característica de haber dejado marginado a grupos sociales de la educación primaria mientras paralelamente establecieron una gran expansión de los niveles superiores constituyéndose en los países de mayor cobertura universitaria de la región. El tercero, se caracteriza por desarrollos educativos más lentos y desiguales según se trate de poblaciones rurales o urbanas y de distintas regiones dentro del país, siguiendo la expansión educativa, el desarrollo económico regional y las líneas de concentración del ingreso. 
La desigual evolución educativa según países se contrasta con la similitud que presenta el fenómeno de la calidad de los conocimientos transmitidos. Como es natural una expansión cuantitativa de la magnitud indicada sólo podría ser realizada al costo de la calidad del conocimiento transmitido para los grupos sociales recientemente incorporados a la educación, que no podían complementarla con la cultura familiar ni tampoco apoyarse en ella para compensar la deficiencia de la educación formal. En este sentido la transformación democrática en términos de volúmenes no se acompañó por una transformación similar en cuanto a naturaleza de la cultura escolar y condiciones de transmisión de conocimientos que siguen siendo concebidas de igual forma que si se tratara de una educación de élites y, por tanto, ineficaz para incluir en una cultura universal a quienes vienen de subculturas tan desiguales como la propia heterogeneidad social de la región.

Más allá de ello subsiste el problema de que la universalización educativa contiene el principio de la selección meritocrática para los distintos puestos sociales, lo que se contradice vivamente con la orientación de los grupos privilegiados que resisten en lo social tal tipo de democratización. La consecuencia de esto es que el espacio educativo se ha transformado implícitamente en un ámbito en el que se ejercen presiones antagónicas: las grandes mayorías reclamando una educación universal y los grupos de cúpula tratando de anular ese efecto igualitario por medio de una estratificación del sistema educativo en el que mientras ciertos circuitos de enseñanza continuarían formando en el más alto nivel científico y académico, los otros, resultantes de la expansión reciente, en virtud de un deterioro de los recursos materiales y humanos y de una aceptación demagógica de las aspiraciones educativas, realizarían una educación de pobre contenido cultural y científico y en el que la aprobación ritual de los cursos sería tan fácil como el ingreso mismo.

\section{Los niveles de instrucción logrados por la población joven}

La información disponible sobre la presente década sólo permite comparar la evolución de los niveles de instrucción de los jóvenes en 4 países de la región y por tanto no se refleja en los ejemplos las categorías precedentemente enunciadas sobre la forma en que se ha operado la transición educativa en la región. Brasil corresponde al tercer conjunto de países con desigualdades considerables según regiones y estratos sociales; Perú es un claro ejemplo de país mutante en materia educativa en tanto que Panamá y Chile tenían ya en los años sesenta algunas de las características de los países de temprana modernización educativa, pero no constituyen los ejemplos por excelencia de la misma.

De acuerdo con los datos del Cuadro No. 1, la exclusión educativa o la escolaridad apenas incipiente de 1 a 3 grados escolares ha pasado a ser un fenómeno residual y en vías de desaparición en Chile y Panamá; para los tramos de edad 15-19 y 20-24 años Perú refleja un enorme esfuerzo educativo que implicó el abatimiento de cifras de excluidos de la educación que se aproximaban a un tercio a un porcentaje del $6.3 \%$ del grupo de edad 15-24 años, mientras finalmente Brasil refleja una lenta transición ya que partiendo de niveles de exclusión similares a los de Perú, sigue teniendo en la condición de $\mathrm{O}$ grado de educación alrededor de 1 de cada 6 jóvenes del grupo de edad 15-19 y si se considera en forma conjunta excluidos y educados de 1 a 3 grados, sigue encontrándose aquí más de un tercio de la población joven. 
CUADRO No.1

NIVELES DEINSTRUCCIÓN DE LA POBLACION JOVEN, SEGÚN SEXO

CHILE, BRASIL, PANAMA Y PERU: 1960-1980

\begin{tabular}{|c|c|c|c|c|c|c|c|c|c|c|c|c|c|c|c|c|c|c|c|c|c|c|c|c|}
\hline & \multicolumn{8}{|c|}{ Ambos sexos } & \multicolumn{8}{|c|}{ Hombres } & \multicolumn{8}{|c|}{ Mujeres } \\
\hline & $\begin{array}{l}\text { Total } \\
\text { miles }\end{array}$ & $\mathbf{0}$ & $1-3$ & $4-6$ & $7-9$ & $\begin{array}{l}10- \\
12 \\
\end{array}$ & $\begin{array}{c}13 y \\
+\end{array}$ & N.D & $\begin{array}{l}\text { Total } \\
\text { miles }\end{array}$ & $\mathbf{0}$ & $1-3$ & $4-6$ & $7-9$ & $\begin{array}{r}10- \\
12 \\
\end{array}$ & $\begin{array}{c}13 y \\
+ \\
\end{array}$ & N.D. & $\begin{array}{l}\text { Total } \\
\text { miles }\end{array}$ & $\mathbf{0}$ & $1-3$ & $4-6$ & $7-9$ & $\begin{array}{l}10- \\
12 \\
\end{array}$ & $\begin{array}{c}13 y \\
+ \\
\end{array}$ & N.D \\
\hline \multicolumn{25}{|l|}{$\begin{array}{c}\text { Chile } \\
\text { Grupo 15-19 } \\
\text { años }\end{array}$} \\
\hline 1960 & 726.2 & 8.3 & 18.4 & 39.4 & 23.9 & 7.3 & 0.2 & 2.3 & 358.3 & 8.8 & 18.7 & 39.1 & 24.2 & 6.9 & 0.3 & 2.1 & 367.9 & 7.9 & 18.2 & 39.8 & 23.8 & 7.8 & 0.2 & 2.5 \\
\hline 1970 & 909.3 & 2.7 & 9.7 & 30.2 & 33.5 & 15.3 & 1.0 & 7.6 & 448.2 & 2.9 & 10.2 & 29.8 & 34.1 & 14.7 & 0.9 & 7.3 & 461.2 & 2.5 & 9.3 & 30.6 & 32.9 & 15.9 & 1.0 & 7.8 \\
\hline 1980 & 1.366 .1 & 1.5 & 2.2 & 14.2 & 28.3 & 40.0 & 2.7 & 1.1 & 702.3 & 1.7 & 2.7 & 15.4 & 39.8 & 36.6 & 2.9 & 0.9 & 663.8 & 1.4 & 1.7 & 13.0 & 36.6 & 43.5 & 2.5 & 1.3 \\
\hline \multicolumn{25}{|l|}{$\begin{array}{c}\text { Grupo 20-24 } \\
\text { años } \\
\end{array}$} \\
\hline 1960 & 596.2 & 10.6 & 18.4 & 37.6 & 15.0 & 11.8 & 2.6 & 4.0 & 283.1 & 10.4 & 18.9 & 36.5 & 15.7 & 11.3 & 3.2 & 4.0 & 313.1 & 10.8 & 18.0 & 38.5 & 14.3 & 12.3 & 2.0 & 4.1 \\
\hline 1970 & 752.9 & 4.2 & 11.1 & 32.1 & 17.4 & 16.7 & 6.5 & 12.0 & 363.2 & 4.1 & 11.1 & 31.4 & 17.8 & 16.4 & 7.3 & 11.8 & 389.8 & 4.3 & 11.0 & 32.8 & 17.8 & 17.0 & 5.7 & 12.1 \\
\hline 1980 & 1.074 .6 & 2.0 & 2.8 & 13.4 & 25.2 & 43.0 & 11.1 & 2.5 & 542.0 & 2.1 & 3.1 & 13.5 & 26.9 & 40.4 & 11.4 & 2.7 & 532.6 & 2.0 & 2.5 & 13.3 & 23.4 & 45.6 & 10.8 & 2.4 \\
\hline \multicolumn{25}{|l|}{$\begin{array}{c}\text { Panamá } \\
\text { Grupo 15-19 } \\
\text { años } \\
\end{array}$} \\
\hline 1960 & 105.2 & 15.9 & 15.5 & 43.3 & 18.3 & 6.6 & 0.2 & 0.1 & 50.9 & 15.0 & 16.8 & 45.1 & 17.2 & 5.7 & 0.1 & 0.1 & 54.3 & 16.8 & 14.4 & 41.7 & 19.3 & 7.4 & 0.3 & 0.1 \\
\hline 1970 & 144.7 & 8.8 & 11.6 & 45.6 & 23.4 & 10.4 & 0.2 & --- & 71.5 & 7.8 & 12.7 & 47.5 & 22.9 & 9.0 & 0.1 & --- & 73.2 & 9.7 & 10.6 & 43.8 & 24.0 & 11.7 & 0.2 & --- \\
\hline 1980 & 200.0 & 4.0 & 4.6 & 32.1 & 33.6 & 23.5 & 1.4 & 0.8 & 99.6 & 3.4 & 5.1 & 34.6 & 33.6 & 21.5 & 1.0 & 0.7 & 100.4 & 4.5 & 4.2 & 29.7 & 33.6 & 25.5 & 1.7 & 0.8 \\
\hline \multicolumn{25}{|l|}{$\begin{array}{c}\text { Grupo 20-24 } \\
\text { años }\end{array}$} \\
\hline 1960 & 92.0 & 21.0 & 17.1 & 36.6 & 11.9 & 10.5 & 2.6 & 0.3 & 46.0 & 21.2 & 18.1 & 36.9 & 10.9 & 10.2 & 2.3 & 0.4 & 46.0 & 20.9 & 16.0 & 36.4 & 12.8 & 10.9 & 2.8 & 0.2 \\
\hline 1970 & 124.9 & 12.2 & 12.9 & 41.5 & 14.1 & 14.3 & 4.8 & 0.2 & 62.3 & 11.7 & 14.0 & 42.1 & 14.2 & 13.1 & 4.6 & 0.2 & 62.7 & 12.7 & 11.8 & 40.8 & 14.0 & 15.5 & 5.0 & 0.1 \\
\hline 1980 & 161.8 & 5.7 & 5.9 & 31.5 & 16.8 & 25.7 & 13.6 & 0.8 & 79.3 & 4.5 & 5.9 & 34.4 & 17.4 & 24.4 & 12.5 & 0.9 & 82.6 & 6.8 & 6.0 & 28.7 & 16.2 & 26.9 & 14.8 & 0.7 \\
\hline \multicolumn{25}{|l|}{$\begin{array}{c}\text { Perú } \\
\text { 15-19 años } \\
\end{array}$} \\
\hline 1961 & 973.7 & 28.5 & 29.9 & 22.7 & 12.4 & 4.7 & 0.3 & 1.4 & 494.0 & 20.0 & 33.6 & 25.9 & 14.1 & 5.0 & 0.4 & 1.1 & 479.7 & 37.3 & 26.1 & 19.4 & 10.8 & 4.5 & 0.3 & 1.7 \\
\hline 1972 & 1.413 .3 & 11.4 & 21.6 & 27.6 & 25.3 & 11.0 & 1.1 & 1.8 & 715.1 & 6.1 & 20.8 & 26.7 & 28.3 & 14.9 & 1.2 & 2.1 & 698.2 & 16.8 & 22.5 & 28.6 & 22.3 & 7.1 & 1.1 & 1.6 \\
\hline \multicolumn{25}{|l|}{$\begin{array}{c}1981 \\
\text { Grupo 20-24 }\end{array}$} \\
\hline $\begin{array}{c}\text { Grupo 20-24 } \\
\text { años } \\
\end{array}$ & & & & & & & & & & & & & & & & & & & & & & & & \\
\hline 1961 & 848.3 & 31.4 & 26.7 & 23.6 & 7.9 & 7.2 & 1.9 & 1.4 & 420.6 & 19.0 & 30.8 & 28.5 & 9.3 & 8.4 & 2.5 & 1.5 & 427.7 & 43.5 & 22.6 & 18.8 & 6.5 & 5.9 & 1.4 & 1.3 \\
\hline 1972 & 1.150 .6 & 14.8 & 20.8 & 23.9 & 13.8 & 17.3 & 6.2 & 3.2 & 572.0 & 7.1 & 19.4 & 25.3 & 16.6 & 21.0 & 7.6 & 3.0 & 578.6 & 22.4 & 22.2 & 22.6 & 11.1 & 13.6 & 4.8 & 3.4 \\
\hline$(15-24) 1981$ & 3.443 .5 & 6.3 & \multicolumn{2}{|c|}{35.9} & \multicolumn{2}{|c|}{45.3} & 9.2 & 3.3 & 1.688 .1 & 3.4 & \multicolumn{2}{|c|}{34.3} & & 49.1 & 9.7 & 3.4 & 1.755 .4 & 9.1 & \multicolumn{2}{|c|}{37.4} & \multicolumn{2}{|c|}{41.6} & 8.7 & 3.2 \\
\hline \multicolumn{25}{|l|}{$\begin{array}{c}\text { Brasil } \\
\text { Grupo 15-19 } \\
\text { años } \\
\end{array}$} \\
\hline 1960 & 7.320 .2 & 35.7 & 32.0 & 21.2 & 6.6 & 3.6 & 0.5 & 0.4 & 3.552 .7 & 36.3 & 31.5 & 20.5 & 7.3 & 3.4 & 0.5 & 0.5 & 3.767 .8 & 35.1 & 32.5 & 21.8 & 6.0 & 3.8 & 0.6 & 0.4 \\
\hline 1970 & 10.256 .5 & 27.9 & 18.9 & 29.2 & 5.9 & 4.2 & 0.2 & 13.5 & 4.987 .5 & 29.2 & 18.9 & 28.8 & 6.1 & 3.9 & 0.2 & 13.0 & 5.269 .0 & 26.8 & 19.0 & 29.6 & 5.7 & 4.6 & 0.2 & 14.0 \\
\hline$* 1980$ & 13.277 .7 & 16.8 & 19.2 & \multicolumn{2}{|c|}{$\begin{array}{l}51.7 \\
\mathbf{4 8}\end{array}$} & 3.0 & 0.5 & --- & 6.488 & 18.7 & 19.3 & \multicolumn{2}{|c|}{50.7} & 10.9 & 0.3 & --- & 6.789 .4 & 14.9 & 19.0 & \multicolumn{2}{|c|}{52.7} & 12.8 & 0.6 & --- \\
\hline $\begin{array}{c}\text { Grupo 20-24 } \\
\text { años } \\
\end{array}$ & $*$ & $\mathbf{0}$ & $1-3$ & & & $9-11$ & $\begin{array}{c}12 y \\
+ \\
\end{array}$ & & $*$ & $\mathbf{0}$ & $1-3$ & \multicolumn{2}{|c|}{$4-8$} & $9-11$ & $\begin{array}{c}12 y \\
+ \\
\end{array}$ & & $*$ & $\mathbf{0}$ & $1-3$ & \multicolumn{2}{|c|}{$4-8$} & 9-11 & $\begin{array}{c}12 y \\
+ \\
\end{array}$ & \\
\hline 1960 & 6.324 .0 & 36.0 & 31.6 & 21.4 & 2.8 & 4.2 & 3.4 & 0.5 & 3.079 .4 & 34.1 & 32.9 & 21.4 & 3.3 & 4.4 & 3.4 & 0.5 & 3.244 .9 & 37.9 & 30.4 & 21.5 & 2.4 & 4.0 & 3.4 & 0.4 \\
\hline 1970 & 8.395 .5 & 33.9 & 16.7 & 26.8 & 4.8 & 3.6 & 2.4 & 11.9 & 4.108 .9 & 33.3 & 16.4 & 27.7 & 5.2 & 4.2 & 2.9 & 10.5 & 4.286 .6 & 34.5 & 16.4 & 26.6 & 4.4 & 3.1 & 1.9 & 13.2 \\
\hline$* 1980$ & 11.626 .4 & 17.3 & 17.2 & 43 & & 16.4 & 5.8 & --- & 5.656 .0 & 17.8 & 17.1 & & & 15.7 & 5.5 & --- & 5.970 .4 & 16.9 & 17.2 & & & 17.1 & 6.1 & --- \\
\hline
\end{tabular}

Digitalizado por RED ACADEMICA 
Los registros de exclusión educativa incipiente permiten apreciar que los logros poco tienen que ver con el producto bruto per cápita o con las tasas de crecimiento del mismo. Todos los países considerados tienen capacidad económica para sostener una educación básica para toda la población. Por tanto las razones de las políticas educativas de países como Panamá y Perú hay que buscarlas en la aspiración a la integración nacional y en las políticas que gobiernos recientes de esos países llevaron a cabo para transformar sociedades marcadamente dualistas en sistemas integrados de comunicación social que dieran base a una identidad colectiva y a condiciones de participación social. En el caso de Chile la aspiración a la movilidad social, en una sociedad constituida como nación pero con grandes clivajes entre los grupos sociales y con manifiestos bloqueos para la movilidad social ascendente, se expresó en fuertes demandas de las clases sociales populares que fueron acogidas en las políticas gubernamentales desde la década del 60; los cambios políticos posteriores que intentaron reintroducir una organización social fuertemente jerarquizada, no lograron detener la demanda social por educación como instrumento de movilidad y participación sociales.

Si se considera que 10 y más años de educación sería el horizonte deseable al que la región tendría que llegar para educar a sus jóvenes con un conjunto de conocimientos que los habilitara tanto para la participación social como para una capacitación indispensable hacia un futuro en el que la ciencia y la tecnología impregnarán progresivamente las sociedades, los logros de algunos países son espectaculares para haber sido realizados en el breve lapso de 20 años.

El caso extremo lo constituye Chile que eleva el porcentaje de población entre 15 y 19 años con 10 y más años de educación del 7.5 al $42.7 \%$ en lo que se expresa la conjunción de aspiraciones sociales y decisiones políticas pero en lo que también incluye un mejoramiento de la eficiencia formal del sistema educativo. Panamá, con un punto de partida ligeramente inferior, llega al $24.9 \%$ mientras que Perú manifiesta en este nivel las distorsiones ya antiguas en su sistema educativo. En el año 1961 Perú registraba 5\% de su grupo de edad 15-19 años en este nivel, cuando mantenía en el analfabetismo funcional a más del $58 \%$ del tramo de edad; en 1981 y para el tramo 15-24 años se puede estimar que tiene más de 10 grados escolares el 35\% del mismo.

Como el retraso en el cumplimiento del ciclo escolar es muy acentuado en este período de transición, por la incidencia del ingreso tardío y la repetición, los logros se registraron mejor en el tramo de edad 20-24 años. En él Chile tiene a más de la mitad con educación avanzada, Panamá casi el $40 \%$ y Brasil partiendo de un 7.6 accede al $22.2 \%$ de jóvenes con educación de 10 y más años, lo que demuestra una vez más el carácter dual de su expansión educativa ya que estos promedios nacionales manifiestan los altos logros de las regiones más desarrolladas y los mínimos de las menos desarrolladas.

Las cifras de Chile y Panamá para las edades 15 y 18 años, permiten establecer que el mejoramiento de los niveles educativos de la población pasan por el incremento del período de permanencia de niños y jóvenes en el sistema educativo y por el mejoramiento de su nivel de eficiencia —-medido por la relación edad-curso- que parecería se incrementa en relación directa con la extensión del ciclo real de escolaridad. Estos resultados sirven para indicar el error de las estrategias que aspiraron y aspiran a un mejoramiento de la educación por medios no formales de atención y también señalan en forma indirecta el papel del Estado en la transformación educativa, ya que ambos países se caracterizaron en el período de expansión educativa porque ella fue resultado de la acción intencional del Estado creando una oferta institucionalizada. 
Así, en Chile la población de 15 años que asistía a la educación en el año 1960 era el $79 \%$ de esa edad y se eleva al $84 \%$ en 1980 , mientras que a los 18 años el cambio es más significativo pasando de un $47 \%$ a un $60 \%$. Paralelamente, la población de 15 años que asistía y ya había alcanzado 10 y más grados escolares era del $2.5 \%$, mientras que en 1980 era el $23.6 \%$ y la de 18 años de edad evoluciona del $22.5 \%$ al $76.4 \%$. La evolución de Panamá es similar pero con registros inferiores porque la eficiencia del sistema educativo es aún menor, pero sigue la misma tendencia que la indicada para Chile.

Inversamente, quienes a las edades indicadas ya no asisten a los establecimientos escolares tienen logros educativos muy bajos que mejoran en forma más leve demostrando que quienes salen del sistema educativo formal son aquellos que lo hacen habiendo logrado limitadas aprobaciones de cursos, que posteriormente no pueden subsanar porque no existe una política de recuperación educativa a cargo del propio sistema educativo formal.

El acceso a la educación de los jóvenes según sexo no presenta para el conjunto de la región latinoamericana indicadores de discriminación y tanto mujeres como hombres si son discriminados lo son por su condición social y no por su condición sexual. Este panorama tiene la excepción en los países con importante volumen de población indígena cuyas pautas culturales de mantención de la mujer en el analfabetismo o en la exclusión educativa - para conservar el acervo a transmitir a las nuevas generaciones para resistir la cultura dominante originada en el colonizador-, parece haberse difundido como pauta de la sociedad toda o al menos en sus grupos cholos o ladinos. Así en el Perú en el año 1961 estaban excluidas de la educación el doble de mujeres que de hombres y aun en 1981 si bien todos los porcentajes descendieron, la distancia se mide por una proporción de 1 a 3 , mientras que los grados postprimarios son alcanzados en mayor medida por los hombres que por las mujeres. El caso contrario es el de Panamá en relación con la instrucción de 10 y más años en que las mujeres tienen registros educativos ligeramente superiores a la de los hombres. En este caso parece influir una socialización anticipatoria en vistas al desempeño de ocupaciones en el sector terciario moderno del mercado de empleo en el que tienen una participación muy superior a la de los hombres. 
CUADRO No. 2

DISTRIBUCION DE LA POBLACION ECONOMICAMENTE ACTIVA DE 20 A 24 AÑOS DE EDAD,

SEGÚN NIVELES DE DISTRIBUCION Y SEXO. CHILE: 1960, 1970 Y 1980

\begin{tabular}{|c|c|c|c|c|c|c|c|c|c|c|c|c|c|c|c|c|c|c|}
\hline & \multicolumn{6}{|c|}{ Ambos Sexos } & \multicolumn{6}{|c|}{ Hombres } & \multicolumn{6}{|c|}{ Mujeres } \\
\hline & $\begin{array}{l}\text { Total } \\
\text { (Miles) }\end{array}$ & $0-3$ & $4-6$ & $7-9$ & $10 y+$ & N.D. & $\begin{array}{c}\text { Total } \\
\text { (Miles) }\end{array}$ & $0-3$ & $4-6$ & $7-9$ & $10 y+$ & N.D. & $\begin{array}{c}\text { Total } \\
\text { (Miles) }\end{array}$ & $0-3$ & $4-6$ & $7-9$ & $10 y+$ & N.D. \\
\hline $\begin{array}{l}1960 \\
\text { Total grupo } 20-24 \text { años }\end{array}$ & 363.9 & 106.3 & 142.1 & 54.6 & 45.6 & 13.3 & 261.7 & 80.8 & 101.7 & 41.3 & 27.8 & 10.1 & 102.1 & 25.5 & 40.3 & 13.3 & 17.9 & 5.1 \\
\hline Profesionales y Técnicos & 4.7 & 0.6 & 1.1 & 5.2 & 16.0 & 32.2 & 2.5 & 0.5 & 1.0 & 1.6 & 9.4 & 18.3 & 10.5 & 0.7 & 1.5 & 16.4 & 26.3 & 60.7 \\
\hline Direc. Gerentes, Propietarios & 0.4 & 0.2 & 0.2 & 0.9 & 1.3 & - & 0.5 & 0.1 & 0.2 & 1.0 & 1.8 & - & 0.3 & 0.3 & 0.2 & 0.6 & 0.5 & - \\
\hline Empleados de oficina & 7.8 & 0.6 & 1.8 & 13.1 & 38.6 & 3.8 & 7.1 & 0.6 & 2.2 & 13.0 & 36.6 & 2.5 & 9.7 & 0.3 & 0.6 & 13.2 & 41.8 & 6.6 \\
\hline Vendedores, Prop. Comercio & 5.1 & 1.6 & 5.6 & 8.4 & 9.2 & 1.6 & 4.9 & 1.3 & 5.3 & 7.5 & 11.5 & 1.7 & 0.7 & 2.6 & 6.4 & 11.3 & 5.6 & 1.6 \\
\hline Trab. Agric., caza, pesca, minas & 26.2 & 50.3 & 23.8 & 5.5 & 3.3 & 23.0 & 35.7 & 64.5 & 32.6 & 7.3 & 5.4 & 35.0 & 2.0 & 5.3 & 1.7 & - & - & - \\
\hline Conductores medios transporte & 2.7 & 0.8 & 3.2 & 5.5 & 1.7 & 4.9 & 3.8 & 1.0 & 4.5 & 7.3 & 2.7 & 7.5 & - & - & & - & - & - \\
\hline Artesanos y operarios & 19.1 & 8.4 & 25.7 & 30.1 & 14.7 & 6.0 & 20.1 & 9.7 & 26.3 & 31.5 & 15.1 & 8.3 & 16.6 & 4.3 & 24.3 & 25.8 & 14.1 & 1.6 \\
\hline Otros operarios en fabricas & 4.4 & 3.8 & 5.8 & 5.7 & 0.9 & 2.2 & 5.1 & 4.3 & 6.6 & 6.1 & 0.9 & 3.3 & 2.9 & 2.3 & 4.0 & 4.4 & 0.9 & \\
\hline Obreros y jornaleros & 5.8 & 7.7 & 7.0 & 3.8 & 0.4 & 4.4 & 7.5 & 9.9 & 8.9 & 4.7 & 0.6 & 5.8 & 1.3 & 1.0 & 2.1 & 1.3 & - & 1.6 \\
\hline Trab. En servicios personales & 16.3 & 21.9 & 19.5 & 10.1 & 2.0 & 11.5 & 4.2 & 3.3 & 4.9 & 6.3 & 1.5 & 3.3 & 47.3 & 80.9 & 56.5 & 22.0 & 2.8 & 27.9 \\
\hline Otros y no declarados & 7.3 & 4.3 & 6.1 & 11.5 & 11.9 & 10.4 & 8.7 & 4.9 & 7.4 & 13.6 & 14.5 & 15.8 & 3.7 & 2.3 & 2.7 & 5.0 & 8.0 & - \\
\hline 1970 & $*(266$ & $(13)$ & $(19)$ & $(29)$ & $(72)$ & $(3,3)$ & $(28)$ & (16) & $(23)$ & $(30)$ & $(7,3)$ & & $(20)$ & $(03)$ & $(0.8)$ & $(25)$ & $870)$ & \\
\hline Total grupo 20-24 años & 425.9 & 64.9 & 146.0 & 76.4 & 84.2 & 54.3 & 301.7 & 50.6 & 108.0 & 56.1 & 50.5 & 36.6 & 124.2 & 14.3 & 38.0 & 20.3 & 33.8 & 17.8 \\
\hline Profesionales y Técnicos & 6.0 & 0.4 & 0.6 & 4.3 & 19.7 & 8.2 & 3.1 & 0.3 & 0.5 & 1.5 & 11.9 & 5.0 & 13.1 & 0.8 & 1.2 & 11.8 & 31.4 & 14.9 \\
\hline Direc. Gerentes, Propietarios & 0.6 & 0.1 & 0.2 & 0.7 & 1.7 & 0.6 & 0.7 & 0.1 & 0.3 & 0.7 & 2.4 & 0.5 & 0.4 & 0.1 & 0.1 & 0.5 & 0.7 & 0.7 \\
\hline Empleados de oficina & 11.3 & 1.1 & 2.3 & 12.2 & 33.5 & 12.0 & 9.4 & 1.0 & 2.3 & 11.3 & 30.8 & 9.9 & 15.9 & 1.8 & 2.4 & 14.8 & 37.6 & 16.2 \\
\hline Vendedores, Prop. Comercio & 6.7 & 3.8 & 5.6 & 9.3 & 8.4 & 6.7 & 6.5 & 3.6 & 5.3 & 8.6 & 8.9 & 7.8 & 7.0 & 4.5 & 6.4 & 11.3 & 7.6 & 4.5 \\
\hline Trab. Agric., caza, pesca, minas & 19.7 & 45.4 & 27.4 & 5.9 & 2.3 & 14.9 & 27.2 & 57.0 & 36.2 & 7.9 & 3.7 & 21.6 & 1.5 & 4.5 & 2.5 & 0.1 & 0.2 & 0.9 \\
\hline Conductores medios transporte & 3.0 & 1.5 & 3.1 & 5.3 & 2.3 & 2.2 & 4.2 & 1.9 & 4.2 & 7.2 & 3.8 & 3.3 & 0.1 & & & 0.1 & 0.1 & \\
\hline Artesanos y operarios & 17.6 & 10.2 & 19.7 & 25.7 & 12.5 & 17.1 & 18.8 & 11.1 & 20.2 & 26.7 & 15.2 & 15.6 & 14.4 & 7.0 & 18.3 & 22.8 & 8.5 & 14.0 \\
\hline Otros operarios en fabricas & 5.2 & 4.2 & 7.0 & 5.8 & 2.0 & 5.4 & 6.2 & 5.0 & 7.9 & 6.7 & 2.8 & 7.0 & 2.5 & 1.5 & 4.2 & 3.2 & 0.9 & 2.0 \\
\hline Obreros y jornaleros & 6.6 & 7.9 & 8.6 & 6.9 & 1.8 & 6.9 & 8.6 & 9.6 & 10.4 & 8.7 & 2.6 & 9.5 & 2.0 & 1.8 & 3.4 & 2.0 & 0.7 & 1.6 \\
\hline Trab. En servicios personales & 13.9 & 18.3 & 18.3 & 12.1 & 3.8 & 14.9 & 4.6 & 3.5 & 4.8 & 6.7 & 3.2 & 4.2 & 36.4 & 70.9 & 56.6 & 26.8 & 4.6 & 36.8 \\
\hline Otros y no declarados & 9.4 & 6.9 & 7.1 & 12.0 & 11.9 & 11.2 & 10.6 & 6.9 & 8.0 & 13.9 & 14.6 & 12.6 & 6.7 & 6.9 & 4.9 & 6.7 & 7.7 & 8.4 \\
\hline & & & & & & & & & & & & & & & & & & \\
\hline 1980 & ${ }^{*}(1.8)$ & $(0.5)$ & $(0.7)$ & $(1.8)$ & $(4.8)$ & (1.7) & $(1.7)$ & $(0.6)$ & $(0.7)$ & $(1.6)$ & $(5.3)$ & $(1.5)$ & $(1.9)$ & $(0.3)$ & $(0.6)$ & (2.1) & $(4.0)$ & $(2.0)$ \\
\hline Total grupo 20-24 años & 639.2 & 28.8 & 92.0 & 180.6 & 321.5 & 16.2 & 424.3 & 23.0 & 67.4 & 134.3 & 188.6 & 10.9 & 214.9 & 5.8 & 24.6 & 46.3 & 132.9 & 5.3 \\
\hline Profesionales y Técnicos & 3.5 & - & 0.1 & 1.2 & 5.9 & 6.0 & 1.7 & - & 0.1 & 0.3 & 3.3 & 3.0 & 7.1 & - & 0.1 & 3.6 & 9.7 & 12.3 \\
\hline Direc. Gerentes, Propietarios & 0.5 & - & - & 0.2 & 0.8 & 0.2 & 0.6 & - & - & 0.2 & 1.2 & 0.2 & 0.2 & - & - & - & 0.2 & \\
\hline Empleados de oficina & 14.9 & 0.3 & 1.2 & 3.8 & 26.3 & 16.3 & 10.0 & 0.4 & 1.0 & 3.7 & 18.6 & 14.6 & 24.7 & - & 1.9 & 4.1 & 37.3 & 19.8 \\
\hline Vendedores, Prop. Comercio & 9.3 & 11.0 & 5.3 & 8.5 & 10.7 & 9.0 & 8.8 & 11.1 & 5.8 & 8.7 & 9.6 & 10.9 & 10.2 & 10.5 & 4.0 & 8.2 & 12.2 & 5.1 \\
\hline Trab. Agric., caza, pesca, minas & 13.3 & 35.7 & 30.4 & 17.5 & 4.1 & 12.6 & 19.1 & 42.6 & 38.3 & 22.9 & 6.7 & 17.2 & 1.9 & 8.4 & 8.7 & 1.8 & 0.3 & 3.3 \\
\hline Conductores medios transporte & 2.4 & 0.7 & 2.3 & 3.4 & 2.0 & 1.6 & 3.6 & 0.4 & 3.1 & 4.6 & 3.4 & 2.4 & 0.1 & - & - & 0.1 & 0.1 & - \\
\hline Artesanos y operarios & 13.3 & 12.2 & 11.8 & 16.8 & 11.8 & 14.9 & 16.5 & 14.1 & 14.5 & 18.1 & 16.2 & 19.2 & 6.9 & 4.6 & 4.5 & 13.0 & 5.5 & 5.9 \\
\hline Otros operarios en fabricas & 3.4 & 4.0 & 3.5 & 4.7 & 2.5 & 3.9 & 4.5 & 4.3 & 4.1 & 6.0 & 7.6 & 5.6 & 1.0 & 2.6 & 1.7 & 0.9 & 0.9 & 0.4 \\
\hline Obreros y jornaleros & 7.0 & 12.8 & 11.4 & 8.5 & 4.5 & 6.3 & 9.3 & 14.0 & 14.0 & 10.1 & 6.6 & 7.9 & 2.5 & 5.2 & 4.1 & 3.8 & 1.5 & 3.0 \\
\hline Trab. En servicios personales & 11.8 & 11.1 & 20.9 & 16.6 & 6.6 & 11.7 & 5.0 & 1.0 & 4.4 & 5.4 & 5.7 & 1.8 & 25.2 & 51.1 & 66.0 & 49.0 & 8.0 & 31.9 \\
\hline Otros y no declarados & 20.6 & 12.2 & 13.2 & 18.8 & 24.7 & 17.5 & 20.8 & 11.5 & 14.7 & 19.9 & 25.0 & 17.0 & 20.3 & 14.7 & 9.1 & 15.5 & 24.3 & 18.3 \\
\hline & $\star * *(19.8)$ & $(12.2)$ & $(12.6)$ & $(18.2)$ & (23.6) & $(17.3)$ & $(19.7)$ & $(11.5)$ & $(13.8)$ & (19.1) & $(23.4)$ & $(16.8$ & $(20.0)$ & $(14.7)$ & $(9.1)$ & $(15.5)$ & $(23.8)$ & $(18.3)$ \\
\hline & & & & & & & & & & & & & Porce & taje de & mplea & as Dom & sticas & \\
\hline & & & & & & & & & & & & 1960 & 41.3 & 75.7 & 48.4 & 12.6 & 2.3 & 24.6 \\
\hline & & & & & & & & & & & & 1970 & 30.7 & 67.8 & 49.6 & 16.1 & 1.6 & 32.5 \\
\hline & & & & & & & & & & & & 1980 & 22.3 & 51.1 & 61.0 & 44.6 & 6.0 & 27.3 \\
\hline
\end{tabular}

* Buscan trabajo por primera vez

** Incluye desocupados

Digitalizado por RED ACADEMICA 


\section{Calificaciones educativas, ocupación y movilidad social}

\section{Los cambios en las calificaciones educativas}

El análisis de las relaciones entre educación y ocupación se ha visto perturbado por aproximaciones conceptuales que no tienen presente el papel de la educación como valor cultural y por otras de tipo metodológico que omiten la distinción entre ocupaciones iniciales y ocupaciones finales en la historia de la vida activa de los individuos. Sobre lo primero, debe señalar-se que la reflexión sociológica no ha podido desprenderse de análisis propios de las sociedades tradicionales en las que la educación se encontraba adscrita a la clase social y por tanto era uno de los indicadores de la congruencia de status. En las sociedades contemporáneas uno de los logros mayores es que las personas a través de la educación adquieran una cultura que les permita consumir y crear bienes culturales y estar en condiciones para participar en sociedades progresivamente complejas. Si se considera como devaluación educativa el desempeño de ocupaciones manuales con educación avanzada, la contrapartida de dicha afirmación sería suponer que la educación sólo debiera expandirse en relación con el incremento de las ocupaciones no manuales y que los manuales no debieran tener más educación que aquella que requieren para el desempeño de sus tareas. Sobre lo segundo, el concepto de que el individuo al salir del sistema educativo es un "producto acabado" apto desde ya para insertarse en el tipo de ocupación para el cual teóricamente fue formado implica negar la importancia de los aprendizajes laborales y la tendencia creciente en las economías contemporáneas al desplazamiento horizontal y vertical de la mano de obra. La importancia de la carrera laboral se incrementa con la generalización de la formación educativa y con la heterogeneidad en términos de calidad de la misma; en una educación elitaria era lógico que la selección social fuera realizada por el sistema educativo, en una educación de masas y en economías que reclaman de iniciativa y de logros resulta lógico que esa selección sea realizada por el mercado de trabajo. La consecuencia es que la distancia que media entre las ocupaciones iniciales de los jóvenes y las ocupaciones al fin de la vida adulta sean mayores que las que registraron las generaciones precedentes.

La transformación de los niveles educativos de la población joven económicamente activa se expresan en los dos países de los que se dispone de información actualizada (Chile y Panamá) en los siguientes rasgos:

a) El grupo de edad 15-19 años registra un descenso en a tasa de participación laboral por efectos del incremento del período de asistencia escolar de forma tal que al postergarse el ingreso a la condición activa mejora el perfil educativo de la población joven en el mercado de trabajo.

b) Los jóvenes activos de 15 a 19 años con educación nula o incipiente (1 a 3 grados) descienden en Chile del $34.6 \%$ en 1960 al $7.9 \%$ en 1980 , tendencia que en Panamá es algo más atenuada porque los porcentajes son del $32.8 \%$ y del $12.0 \%$. En el tramo de edad siguiente, de 20 a 24 años, se manifiesta en forma más clara la tendencia a la desaparición del mercado de empleo de jóvenes no educados que en Chile es del $4.5 \%$ y en Panamá del $8.8 \%$ en 1980.

c) Los niveles de educación postprimaria mensurados en el grupo de edad 20-24 años que es el que está en condiciones teóricas de haberlos realizado- evolucionan en Chile del $27.5 \%$ al $75.6 \%$ y en Panamá del $29.9 \%$ al $59.1 \%$. En forma más precisa aquellos que tienen 10 y más años de estudios aprobados son la mitad de los jóvenes chilenos y el $42 \%$ de los panameños que se encuentran en el mercado de trabajo. 
Si se supusiera que los más altamente educados tendrían que obtener ocupaciones no manuales y en las categorías más jerarquizadas de profesionales y semiprofesionales y gerentes y directivos, éstas tendrían que haber multiplicado por 4 en Chile y por 2.1/2 veces en Panamá no sólo en términos absolutos sino acompañando el crecimiento poblacional de los nuevos demandantes de trabajo, es decir, que esos índices de crecimiento tendrían que ser del porcentaje de dichas categorías socio-ocupacionales en el total de la población económicamente activa. No sólo la transformación implicaría tasas de crecimiento económico muy superiores a las históricamente conocidas, sino que paralelamente tendría que haberse producido una revolución tecnológica que provocara una demanda cualitativamente distinta en el perfil de conocimientos de la mano de obra, y asimismo una radical modificación del patrón de distribución de los ingresos para generar un conjunto elevado de ocupaciones en servicios tales como educación salud, ocio, etc., que son los que reclutan en mayor porcentaje a personas altamente educadas.

\section{Los cambios en la estructura ocupacional}

Las principales líneas de los mismos se expresan en las siguientes constataciones:

a)En la población entre 20 y 24 años en ambos países las ocupaciones agrícolas y mineras descienden en su participación porcentual en la PEA alrededor de la mitad; esto significa en el caso de Panamá el desplazamiento de un $21 \%$ de ocupaciones totales a las otras ramas de actividad y en el caso de Chile de una relocalización del $13 \%$ de la PEA juvenil.

b)El conjunto de las ocupaciones no manuales se incrementa en los dos países, en cuanto participación en la PEA total juvenil, en un $50 \%$ manteniéndose la mayor significación que estas ocupaciones tienen en Panamá que en Chile, a pesar de que las ocupaciones agrícolas aportan un porcentaje mayor al total de la PEA en el primero que en el segundo país.

c) Las ocupaciones obreras industriales y de conductores de medios de transporte en el caso de Chile, registran un descenso del orden de un quinto mientras que en Panamá inicialmente hacia el año 1970 tienen un incremento considerable para retornar hacia 1980 a un punto intermedio entre los dos primeros períodos censales.

d) Las tareas de mano de obra no calificada en el sector productivo y de servicios personales, - que en el caso de Panamá implican que la mitad de las mujeres ocupadas a lo largo de las tres fechas observadas trabajen como empleadas domésticas y que en el caso de Chile comprendan entre el $41 \%$ en 1960 y el $22 \%$ en 1980 - , en Panamá se mantiene como porcentaje estable de la PEA mientras que en Chile retroceden en forma regular aunque no acentuada.

e) La desocupación o el período prolongado de búsqueda de trabajo se incrementa en Panamá —aunque las cifras de 1980 no permiten desglosar-las de la categoría ocupacional "otros" - mientras que en el caso de Chile adquieren dimensiones catastróficas ya que entre 1970 y 1980 se pasó de una situación de pleno empleo medida por un reducido $1.8 \%$ de desocupados a $19.8 \%$ de la PEA en 1980.

Los cambios indicados muestran que en el período considerado se asistió a un proceso de transformación estructural como efecto de un cambio acelerado en la participación rural en la PEA nacional, proceso que en Chile está prácticamente finalizado y que 
Panamá tiene muy pocos grados de posible descenso en el futuro. Es muy importante tener presente que en el cambio de destinos ocupacionales manuales-agrícolas a otros urbanos implicó un objetivo ascenso social para los jóvenes que en el transcurso de una generación - a veces en la misma familia - vieron modificarse sus expectativas de futuro, entre un destino agrícola que en los países latinoamericanos es poco halagüeño por las perspectivas de integrarse a una vida urbana que, aun en el supuesto de ocupaciones mal remuneradas y poco prestigiosas, depara sin embargo la posibilidad de integrarse a un circuito de comunicaciones sociales y culturales y a un mayor acceso a los servicios de la sociedad. Este factor dejará de actuar en el futuro y la estructura ocupacional tendrá necesariamente una cristalización considerable, lo que traslada el tema de las expectativas de movilidad ascendente al mejoramiento de las condiciones de trabajo, de remuneración y de status de las ocupaciones hoy consideradas inferiores.

El incremento porcentual en la PEA total de las ocupaciones no manuales provino en el período de los efectos acumulados de la urbanización, el desarrollo de los servicios comerciales y financieros y el crecimiento espectacular de los servicios sociales a cargo del Estado -entre los cuales la propia educación ha sido el más importante- que no podría mantener la misma aceleración en los años siguientes de no mediar incrementos sustanciales de la productividad de los sectores productivos de bienes como para financiar a los sectores sociales, lo que a su vez debería acompañarse de una modificación de la distribución del ingreso para que los sectores menos favorecidos de la sociedad registraran incrementos en su participación en los bienes colectivos por la vía del mejoramiento del ingreso social y del monetario.

Es de anotar que al interior de las ocupaciones no manuales se produce un incremento más acelerado de aquellas que corresponden a un menor status, como las de empleados de oficina y de vendedores, y que en el caso de Chile se produce una caída en la participación porcentual de profesionales y técnicos en la totalidad de la PEA.

En el caso chileno las cifras del año 1980 manifiestan los efectos de una política económica y social que redujo en forma drástica las posibilidades de empleo en forma paralela a una disminución de las funciones sociales y científico-técnicas del Estado, con la consiguiente reducción de las oportunidades de empleo para las generaciones jóvenes altamente educadas.

\section{Los cambios en el perfil educativo de las ocupaciones}

La desigualdad de movimientos en los cambios de las estructuras de las ocupaciones y de la educación motiva que la distribución de los diversos niveles educativos según categorías ocupacionales y la composición de cada categoría educacional según educación, se modifican a la vez que la matriz de cambio incluye también el incremento desigual de los volúmenes de personas que integran los distintos niveles educativos.

Las principales líneas de este conjunto de modificaciones son las siguientes:

a)El nivel educativo 0 - 3 años de estudio se reduce a una cuarta parte en términos absolutos en la PEA de 20 - 24 años en Chile y a la mitad en la respectiva de Panamá. En Panamá la condición de semianalfabeto sigue determinando en dos terceras partes a sus integrantes a la ocupación de agricultores cuando en 1960 lo hacía con los cuatro quintos. En Chile desde la fecha inicial el destino agrícola sólo comprendía a 1 de cada 2 de los escasamente educados y hoy lo hace con 1 de cada 3 . El segundo destino ocupacional para esta categoría en ambos países son las actividades de jornaleros y de 
servicios personales, pero mientras en Panamá las restantes inserciones ocupacionales son mínimas, en Chile un sector superior al tercio restante se distribuye casi por partes iguales entre los empleados, los obreros y los desocupados.

\section{CUADRO No.3 \\ DISTRIBUCION DE LA POBLACION ECONOMICAMENTE ACTIVA DE 20 A 24 AÑOS DE EDAD SEGÚN NIVELES DE INSTRUCCIÓN Y SEXO \\ PANAMA: 1960,1979 Y 1980}

\begin{tabular}{|c|c|c|c|c|c|c|c|c|c|c|c|c|c|c|c|}
\hline Total país & $\begin{array}{l}\text { Total } \\
\text { (miles) }\end{array}$ & $0-3$ & $4-6$ & $7-9$ & $\begin{array}{l}10 y \\
+\quad\end{array}$ & $\begin{array}{l}\text { Total } \\
\text { (miles) }\end{array}$ & $0-3$ & $4-6$ & $7-9$ & $\begin{array}{l}10 y \\
+\quad\end{array}$ & $\begin{array}{l}\text { Total } \\
\text { (miles) }\end{array}$ & $0-3$ & $4-6$ & $7-9$ & $\begin{array}{l}10 y \\
+\end{array}$ \\
\hline \multicolumn{16}{|l|}{ Panamá: 1960 } \\
\hline $\begin{array}{l}\text { Total grupo } 20-24 \\
\text { años }\end{array}$ & 53.1 & 16.3 & 20.8 & 6.9 & 9.0 & 39.8 & 14.6 & $16 . .0$ & 4.4 & --- & 13.3 & 1.6 & 4.8 & 2.5 & 4.4 \\
\hline $\begin{array}{ll}\text { Profesionales } & y \\
\text { técnicos } & \end{array}$ & 5.3 & 0.4 & 1.0 & 3.2 & 26.2 & 2.3 & 0.4 & 0.9 & 2.7 & 13.1 & 14.3 & --- & 1.3 & 4.1 & 39.9 \\
\hline $\begin{array}{l}\text { Direct., Gerentes, } \\
\text { propietarios }\end{array}$ & 9.9 & --- & 0.4 & 1.2 & 3.6 & 1.2 & --- & 0.5 & 1.4 & 7.0 & 0.2 & --- & --- & 0.8 & --- \\
\hline $\begin{array}{l}\text { Empleados de } \\
\text { oficina }\end{array}$ & 9.6 & 0.1 & 4.1 & 13.7 & 36.5 & 5.7 & --- & 3.0 & 6.8 & 32.3 & 21.1 & 1.2 & 7.5 & 26.0 & 40.8 \\
\hline $\begin{array}{l}\text { Vendedores, prop. } \\
\text { Comercio }\end{array}$ & 6.0 & 1.7 & 6.8 & 15.5 & 4.7 & 5.1 & 1.7 & 5.4 & 15.1 & 5.7 & 8.6 & 2.5 & 11.3 & 16.7 & 3.7 \\
\hline $\begin{array}{l}\text { Trab. Agric.,Caza } \\
\text { pesca minas }\end{array}$ & 42.9 & 83.8 & 40.3 & 9.4 & 1.6 & 55.7 & 90.6 & 50.8 & 14.6 & 3.1 & 4.7 & 22.2 & 5.4 & --- & --- \\
\hline $\begin{array}{l}\text { Conductores medios } \\
\text { transporte }\end{array}$ & 2.5 & 1.0 & 3.4 & 4.1 & 2.2 & 3.4 & 1.1 & 4.4 & 6.4 & 7.4 & --- & --- & --- & --- & --- \\
\hline $\begin{array}{ll}\begin{array}{l}\text { Artesanos } \\
\text { operarios }\end{array} & y \\
\end{array}$ & 7.4 & 1.9 & 9.0 & 14.3 & 8.5 & 8.2 & 4.1 & 9.9 & 17.8 & 15.3 & 5.1 & 2.6 & 5.9 & 8.1 & 1.4 \\
\hline $\begin{array}{l}\text { Otros operarios en } \\
\text { fábricas }\end{array}$ & 2.8 & 0.9 & 4.5 & 4.7 & 0.7 & 3.3 & 0.8 & 5.4 & 5.5 & 1.3 & 1.9 & 1.2 & 1.3 & 3.3 & --- \\
\hline Obreros y jornaleros & 4.2 & 1.4 & 6.1 & 7.6 & 2.5 & 5.5 & 1.5 & 7.9 & 10.0 & 4.8 & 0.6 & --- & --- & 3.3 & --- \\
\hline $\begin{array}{l}\text { Trab. En servicios } \\
\text { personales }\end{array}$ & 12.0 & 17.4 & 18.1 & 15.8 & 3.1 & 4.6 & 1.7 & 5.9 & 10.0 & 3.9 & 34.1 & 59.3 & 58.6 & 26.0 & 2.3 \\
\hline $\begin{array}{ll}\begin{array}{l}\text { Otros y } \\
\text { declarados }\end{array} & \text { no } \\
\end{array}$ & 6.2 & 1.5 & 6.5 & 10.5 & 10.5 & 4.9 & 1.1 & 5.8 & 9.6 & 9.2 & 10.1 & 4.9 & 8.8 & 12.2 & 11.9 \\
\hline Panamá 1970 & $*(4.2)$ & $(0.9)$ & $(3.8)$ & $(7.9)$ & $(8.5)$ & $(2.9)$ & $(0.4)$ & $(3.0)$ & $(6.8)$ & $(6.6)$ & $(8.3)$ & $(4.9)$ & $(6.3)$ & $(9.8)$ & $(10.6)$ \\
\hline $\begin{array}{l}\text { Total grupo 20-24 } \\
\text { años }\end{array}$ & 83.3 & 18.1 & 34.3 & 12.3 & 18.6 & 58.3 & 15.4 & 25.3 & 8.1 & 9.4 & 25.0 & 2.7 & 8.9 & 4.3 & 9.2 \\
\hline $\begin{array}{ll}\text { Profesionales } & y \\
\text { técnicos } & \\
\end{array}$ & 5.5 & 0.2 & 1.0 & 3.2 & 20.5 & 3.2 & 0.1 & 0.9 & 2.8 & 14.7 & 10.9 & 0.6 & 1.2 & 4.0 & 26.5 \\
\hline $\begin{array}{l}\text { Direct., Gerentes, } \\
\text { propietarios }\end{array}$ & 1.0 & 0.1 & .03 & 0.7 & 3.1 & 1.2 & 0.2 & 0.4 & 1.1 & 5.1 & 0.4 & --- & 0.2 & --- & 1.0 \\
\hline $\begin{array}{l}\text { Empleados de } \\
\text { oficina }\end{array}$ & 12.3 & 0.3 & 3.4 & 14.1 & 39.1 & 6.5 & 0.3 & 2.4 & 9.5 & 25.0 & 25.7 & 0.6 & 6.2 & 22.8 & 53.4 \\
\hline $\begin{array}{l}\text { Vendedores, prop. } \\
\text { Comercio }\end{array}$ & 6.7 & 1.7 & 7.3 & 11.5 & 7.3 & 6.2 & 1.5 & 6.4 & 10.7 & 9.7 & 0.8 & 3.0 & 9.7 & 13.1 & 4.8 \\
\hline $\begin{array}{l}\text { Trab. Agric.,Caza } \\
\text { pesca minas }\end{array}$ & 30.5 & 75.4 & 32.1 & 4.2 & 1.4 & 42.0 & 83.7 & 42.6 & 6.3 & 2.6 & 3.9 & 27.5 & 2.4 & 0.2 & 0.2 \\
\hline $\begin{array}{l}\text { Conductores medios } \\
\text { transporte }\end{array}$ & 3.0 & 0.7 & 4.1 & 4.9 & 1.7 & 4.2 & 0.8 & 5.6 & 7.4 & 3.2 & 0.1 & --- & 0.1 & 0.1 & 0.1 \\
\hline $\begin{array}{ll}\begin{array}{l}\text { Artesanos } \\
\text { operarios }\end{array} & y \\
\end{array}$ & 12.1 & 4.5 & 13.6 & 22.9 & 9.7 & 14.7 & 4.0 & 15.5 & 29.7 & 17.4 & 6.1 & 7.4 & 2.4 & 10.1 & 1.7 \\
\hline $\begin{array}{l}\text { Otros operarios en } \\
\text { fábricas }\end{array}$ & 2.8 & 1.7 & 3.9 & 4.1 & 0.8 & 3.4 & 1.7 & 4.7 & 5.1 & 1.3 & 1.2 & 1.7 & 1.5 & 2.3 & 0.3 \\
\hline Obreros y jornaleros & 5.2 & 3.3 & 7.1 & 7.4 & 2.0 & 6.7 & 3.6 & 8.8 & 9.7 & 3.6 & 1.7 & 1.3 & 2.2 & 3.2 & 0.5 \\
\hline $\begin{array}{l}\text { Trab. En servicios } \\
\text { personales }\end{array}$ & 13.8 & 9.4 & 20.7 & 16.2 & 3.9 & 6.6 & 2.3 & 8.6 & 10.7 & 4.9 & 30.5 & 50.2 & 55.0 & 26.7 & 2.9 \\
\hline $\begin{array}{lll}\text { Otros y } & \text { no } \\
\text { declarados } & \\
\end{array}$ & 7.2 & 2.7 & 6.4 & 10.6 & 10.5 & 5.2 & 1.8 & 4.1 & 7.0 & 12.5 & 11.6 & 7.0 & 13.2 & 17.5 & 8.5 \\
\hline Panamá 1980 & $*(5.8)$ & $(2.4)$ & $(5.8)$ & $(9.2)$ & $(6.9)$ & $(3.6)$ & $(1.5)$ & $(3.4)$ & $(5.2)$ & $(6.0)$ & $(11.1)$ & $(7.4)$ & $(12.7)$ & $(16.8)$ & $(7.9)$ \\
\hline $\begin{array}{l}\text { Total grupo } 20-24 \\
\text { años }\end{array}$ & 94.2 & 8.3 & 29.9 & 16.1 & 39.6 & 63.0 & 6.8 & 24.1 & 11.5 & 20.5 & 31.2 & 1.6 & 5.8 & 4.7 & 19.1 \\
\hline $\begin{array}{ll}\text { Profesionales } & y \\
\text { técnicos } & \\
\end{array}$ & 7.3 & 0.2 & 0.8 & 2.9 & 15.4 & 4.1 & 0.1 & 0.6 & 1.7 & 10.9 & 13.6 & 0.6 & 1.6 & 5.9 & 20.2 \\
\hline $\begin{array}{l}\text { Direct., Gerentes, } \\
\text { propietarios }\end{array}$ & 2.0 & 0.1 & 0.5 & 1.3 & 3.8 & 2.3 & 0.1 & 0.6 & 1.7 & 5.5 & 1.2 & --- & 0.3 & 0.3 & 1.9 \\
\hline $\begin{array}{l}\text { Empleados de } \\
\text { oficina }\end{array}$ & 16.2 & 0.3 & 2.3 & 9.1 & 3.3 & 8.1 & 0.1 & 1.7 & 6.2 & 18.4 & 32.4 & 1.0 & 4.7 & 6.1 & 47.6 \\
\hline $\begin{array}{l}\text { Vendedores, prop. } \\
\text { Comercio }\end{array}$ & 6.0 & 1.3 & 5.4 & 7.9 & 6.7 & 5.6 & 1.2 & 4.8 & 6.6 & 7.5 & 6.9 & 1.9 & 8.1 & 11.0 & 5.9 \\
\hline $\begin{array}{l}\text { Trab. Agric.,Caza } \\
\text { pesca minas }\end{array}$ & 21.6 & 67.2 & 39.2 & 11.0 & 3.1 & 31.2 & 76.3 & 47.8 & 15.3 & 5.7 & 2.4 & 28.0 & 3.9 & 0.3 & 0.3 \\
\hline $\begin{array}{l}\text { Conductores medios } \\
\text { transporte }\end{array}$ & 3.1 & 1.2 & 3.2 & 6.3 & 2.1 & 4.5 & 1.5 & 3.9 & 8.8 & 3.8 & 0.2 & --- & 0.3 & 0.1 & 0.2 \\
\hline $\begin{array}{ll}\begin{array}{l}\text { Artesanos } \\
\text { operarios }\end{array} & y \\
\end{array}$ & 11.9 & 6.0 & 13.0 & 18.9 & 9.5 & 15.7 & 5.2 & 14.3 & 2.5 & 16.8 & 4.3 & 9.5 & 7.3 & 9.9 & 1.6 \\
\hline $\begin{array}{l}\text { Otros operarios en } \\
\text { fábricas }\end{array}$ & 1.9 & 1.3 & 3.0 & 1.8 & 1.3 & 2.6 & 1.6 & 3.4 & 2.1 & 2.3 & 0.6 & --- & 1.4 & 1.1 & 0.3 \\
\hline Obreros y jornaleros & 4.2 & 3.2 & 5.3 & 6.5 & 2.6 & 5.7 & 3.8 & 6.1 & 8.4 & 4.4 & 1.2 & 1.0 & 2.1 & 1.9 & 0.7 \\
\hline
\end{tabular}




\begin{tabular}{|l|l|l|l|l|l|}
\hline \multicolumn{5}{|c|}{ Porcentaje de Empleadas Domésticas } \\
\hline 1960 & 29.4 & 56.8 & 49.9 & 21.1 & 1.4 \\
\hline 1970 & 24.8 & 46.1 & 46.4 & 17.3 & 1.2 \\
\hline 1980 & 15.9 & 29.3 & 47.8 & 23.0 & 3.2 \\
\hline
\end{tabular}

*Buscan trabajo por primera vez

**Incluye desocupados

FUENTES:

Chile y Panamá 1960, 1970 (OMUECE)

Chile 1980

(INE)

Panamá 1980

población de 1980

Perú 1960, 1970, 1980

Brasil 1960, 1970

(OMUECE)

Brasil 1980
Tabulaciones especiales de datos censales

Encuesta Nacional del Empleo Octubre-Diciembre

Tabulaciones especiales de muestra del censo de

Datos censales publicados (INE)

Tabulaciones especiales de datos censales

\section{Datos censales publicados (IBGE)}

b) El nivel educativo 7 - 9 años multiplica sus efectivos absolutos por algo más de 2 en Panamá y por 3,5 veces en Chile. En Chile en el año 1960 más del 400/o de este nivel tenía como destino ocupacional la posición de conductores y obreros, y la segunda inserción que comprendía a más de 0.25 de ella era la categoría de empleados, vendedores y profesionales. En 1980 las inserciones se modificaron totalmente ya que la primera que comprende a 0.25 de los efectivos es la de jornaleros y servicios personales, mientras otro 0.25 se incluye en la categoría de conductores y de obreros, compartiendo finalmente el tercer lugar con un 180/o, aproximadamente, las categorías de desocupados y de agricultores; la otrora inserción dominante en la categoría de empleados pasó a ser el destino ocupacional de sólo 1 de cada 8 personas.

En Panamá la línea de los cambios es similar aunque no tan aguzada. En 1960 un tercio de los jóvenes de 20 - 24 años con 7 años de estudios se ocupaba como empleados y profesionales, mientras otros dos cuartos ingresaban respectivamente a las condiciones de jornaleros y servicios personales, y de obreros. En 1980 este nivel educativo se encuentra con participaciones muy similares en todas las condiciones socio-ocupacionales; poco más de 0.25 de ellos está ocupado como conductores y obreros mientras otro 0.25 está como jornaleros y servicios personales; un quinto llega a la condición de empleados - lo que indica una caída menor que en Chile- y los restantes se distribuyen casi por partes iguales entre otras actividades y desocupados por una parte, y agricultores por la otra.

c)El nivel educativo de 10 y más años de estudio tiene como multiplicador en Panamá el factor 4 y en Chile el factor 7 , expansiones que determinan necesariamente un descenso en la inserción en la categoría socio-profesional de empleados, vendedores y profesionales. En Panamá en 1960 éste era el destino del 710/o y desciende en 1980 a poco menos del 600/o, mientras que en Chile comprendía a dos tercios y ahora lo hace para apenas el 430/o. En este último país el segundo destino de los altamente educados es la desocupación que comprende a casi 0.25 de este nivel educativo en 1980, mientras en Panamá debe situarse como destino de 1 de cada 8 altamente educados. La tercera inserción ocupacional en ambos países es la de conductores de medios de transporte y obreros industriales, siendo algo superior su incorporación en Chile. Las posiciones de jornaleros y de servicios personales de las que estaban prácticamente excluidos en 1960 hoy comprenden al $11 \%$ del nivel educativo en Chile y casi el $9 \%$ en Panamá. 
Si bien por la brevedad del texto no es posible realizar un análisis específico por sexo, debe anotarse que la desocupación femenina en Panamá en 1980 es mayor que la masculina en razón de los más elevados niveles educacionales y de las expectativas de inserción en las ocupaciones no manuales modernas. Algunas inserciones ocupacionales femeninas que en el pasado eran reputadas como exclusivas de las no educadas, tienden a ser comunes para todos los niveles educacionales. La categoría de empleadas domésticas comprende hoy a casi el 160/o de todas las mujeres de 20 a 24 años de Panamá y en esta ocupación están incorporadas casi la mitad de las mujeres entre 4 y 6 años de estudios y 0.25 de quienes tienen 0 - 3 años de estudios y también de quienes tienen 7 - 9 años de estudio. En Chile la participación del empleo doméstico en la ocupación de las jóvenes en 1980 es aún mayor porque comprende al $22 \%$ de ellas, con la característica de que si bien los guarismos más importantes se encuentran en los niveles de educación 4 - 6 años (61\%) y 7 a 9 años de estudios (44.6\%), incluso el nivel de educación más elevado aporta a esta condición ocupacional al $6 \%$ de las jóvenes.

Mirado el fenómeno del cambio de los niveles educativos a partir de la composición de las categorías socio-profesionales, la visión se modifica parcialmente porque dichas categorías no sólo cambiaron de volumen sino en participación en la PEA total. Las principales tendencias han sido las siguientes:

a)La categoría de empleados, vendedores y profesionales no sólo incrementa su participación en la PEA total sino que paralelamente registra una mayor uniformidad en cuanto a los niveles educativos que la integran. Los que tienen 10 y más años de estudio pasan en Chile de ser el $49^{\%}$ en 1960 al $80 \%$ en 1980 , mientras que en Panamá el punto de partida es un poco más elevado (55\%) y el punto de llegada prácticamente idéntico $(79 \%)$.

b) La categoría socio-ocupacional integrada por obreros y conductores de medios de transporte registra una profunda modificación en el nivel educativo de sus miembros. Los más altamente educados que aportaban el $15 \%$ en 1960 en Panamá, pasan a constituir el $32 \%$ en 1980 . En Chile el proceso es aún más acelerado puesto que de un $9 \%$ en 1960 se llega en 1980 a que el $44 \%$ de los obreros tenga 10 y más años de educación.

c) Pero donde el cambio es aún más significativo es en la categoría que agrega los jornaleros y los servicios personales. Ambas categorías están sumadas a los efectos del análisis por la similitud que ostentan en su distribución educativa, en el primer caso en los hombres y en el segundo en las mujeres, ya que se trata de inserciones netamente definidas por el sexo, pero que tienen en común un ejercicio de tareas con poca calificación o incluso cuando la tienen, disminuida por la dependencia altamente personalizada que se registra en las relaciones laborales. 


\section{CUADRO No. 4}

PANAMÁ

DISTRIBUCIÓN DE LA POLBLACIÓN ECONÓMICAMENTE ACTIVA DE 15-19 Y 20-24 AÑOS DE EDAD SEGÚN NIVELES DE INSTRUCCIÓN Y CATEGORÍAS SOCIOOCUPACIONALES AGREGADAS

\begin{tabular}{|c|c|c|c|c|c|c|c|c|c|c|}
\hline \multirow{3}{*}{ CATEGORÍAS } & \multicolumn{5}{|c|}{$15-19$ años } & \multicolumn{5}{|c|}{ 20-24 años } \\
\hline & \multicolumn{10}{|c|}{ Niveles de Educación } \\
\hline & Total & 0-3 & $0-6$ & $7-9$ & $10 y+$ & Total & $0-3$ & $0-6$ & $7-9$ & $10 y+$ \\
\hline 1960(Miles) & $(42.8)$ & $(14.0)$ & $(37.2)$ & $(3.4)$ & $(2.0)$ & $(53.1)$ & $(16.3)$ & $(37.1)$ & $(6.9)$ & $(9.0)$ \\
\hline Empleados, Vend. Profes. & 10.3 & 1.0 & 5.3 & 32.0 & 64.4 & 21.8 & 2.2 & 7.8 & 33.6 & 71.0 \\
\hline Agricultores & 53.2 & 81.5 & 60.6 & 5.3 & --- & 42.9 & 83.8 & 59.4 & 9.4 & 1.6 \\
\hline Conductores y obreros & 6.8 & 2.6 & 5.9 & 16.4 & 6.0 & 12.7 & 3.8 & 11.1 & 23.1 & 11.4 \\
\hline Jornaleros y Serv. Pers. & 18.9 & 11.9 & 19.4 & 20.5 & 7.0 & 16.2 & 8.8 & 17.4 & 23.4 & 5.6 \\
\hline Otros & 1.4 & 0.3 & 1.1 & 4.6 & 3.0 & 2.0 & 0.6 & 1.8 & 2.6 & 2.0 \\
\hline Buscan trabajo y desocupados & 9.3 & 2.7 & 7.6 & 21.1 & 19.8 & 4.2 & 0.9 & 2.5 & 7.9 & 8.5 \\
\hline 1970 (miles) & $(66.6)$ & $(15.9)$ & $(54.6)$ & $(8.0)$ & $(4.0)$ & $(83.3)$ & $(18.1)$ & $(52.4)$ & $(12.3)$ & $(18.6)$ \\
\hline Empleados, Vend. Profes. & 10.5 & 1.2 & 5.3 & 22.5 & 58.8 & 25.5 & 2.3 & 8.0 & 29.5 & 70.0 \\
\hline Agricultores & 40.1 & 71.8 & 48.0 & 6.6 & 1.0 & 30.5 & 75.4 & 47.6 & 4.2 & 1.4 \\
\hline Conductores y obreros & 9.8 & 4.2 & 8.6 & 19.2 & 7.7 & 17.9 & 6.9 & 16.5 & 31.9 & 12.2 \\
\hline Jornaleros y Serv. Pers. & 25.1 & 15.9 & 26.2 & 25.8 & 9.4 & 19.0 & 12.7 & 22.6 & 23.6 & 5.9 \\
\hline Otros & 0.7 & 0.5 & 0.7 & 0.9 & 1.0 & 1.4 & 0.3 & 0.5 & 1.4 & 3.6 \\
\hline Buscan trabajo y desocupados & 13.7 & 6.4 & 11.4 & 25.0 & 22.3 & 5.8 & 2.4 & 4.6 & 9.2 & 6.9 \\
\hline 1980 (miles) & $(56.2)$ & $(6.8)$ & $(37.2)$ & $(11.1)$ & $(7.8)$ & $(94.2)$ & $(8.3)$ & $(38.2)$ & $(16.1)$ & $(39.6)$ \\
\hline Empleados, Vend. Profes. & 10.2 & 1.5 & 4.0 & 11.9 & 37.3 & 31.5 & 1.9 & 7.5 & 21.2 & 58.9 \\
\hline Agricultores & 39.1 & 70.7 & 52.5 & 19.4 & 4.3 & 21.6 & 67.2 & 45.3 & 11.0 & 3.1 \\
\hline Conductores y obreros & 10.4 & 4.4 & 7.8 & 18.1 & 11.4 & 15.9 & 8.5 & 16.9 & 27.0 & 12.9 \\
\hline Jornaleros y Serv. Pers. & 23.6 & 12.0 & 23.2 & 31.4 & 13.9 & 16.5 & 12.6 & 20.6 & 25.9 & 8.6 \\
\hline Otros Buscan trabajo y desocupados & 16.6 & 11.4 & 12.4 & 19.1 & 33.0 & 13.5 & 9.7 & 9.6 & 15.0 & 16.5 \\
\hline
\end{tabular}

\section{CUADRO No.5 \\ CHILE}

DISTRIBUCION DE LA POBLACIÓN ECONOMICAMENTE ACTIVA DE 15-19 Y 20-24 AÑOS DE EDAD SEGÚN NIVELES DE INSTRUCCIÓN Y CATEGORÍAS SOCIOOCUPACIONALES AGREGADAS

\begin{tabular}{|c|c|c|c|c|c|c|c|c|c|c|}
\hline \multirow{3}{*}{ CATEGORÍAS } & \multicolumn{5}{|c|}{ 15-19 Años } & \multicolumn{5}{|c|}{ 20-24 Años } \\
\hline & \multicolumn{10}{|c|}{ Niveles de Educación } \\
\hline & Total & $0-3$ & $0-6$ & $7-9$ & $10 \mathrm{y}+$ & Total & $0-3$ & $0-6$ & $7-9$ & $10 \mathrm{y}+$ \\
\hline 1960(Miles) & $(312.0)$ & $(107.8)$ & $(247.9)$ & $(45.5)$ & $(10.3)$ & $(363.9)$ & $(106.3)$ & $(248.4)$ & $(54.6)$ & $(45.6)$ \\
\hline Empleados, Vend. Profes. & 6.0 & 3.7 & 6.3 & 22.0 & 48.7 & 18.0 & 3.0 & 6.3 & 27.6 & 65.1 \\
\hline Agricultores & 30.4 & 48.1 & 36.2 & 4.2 & 1.6 & 26.2 & 50.3 & 35.1 & 5.5 & 3.3 \\
\hline Conductores y obreros & 17.7 & 8.7 & 16.4 & 27.0 & 15.4 & 26.2 & 13.0 & 25.4 & 41.3 & 17.3 \\
\hline Jornaleros y Serv. Pers. & 22.9 & 27.9 & 26.1 & 11.8 & 4.0 & 22.1 & 29.6 & 27.8 & 13.9 & 2.4 \\
\hline Otros & 8.2 & 3.9 & 6.3 & 18.9 & 5.7 & 4.7 & 3.0 & 3.7 & 8.6 & 4.7 \\
\hline Buscan trabajo y desocupados & 10.8 & 7.8 & 9.0 & 16.2 & 24.4 & 2.6 & 1.3 & 1.6 & 2.9 & 7.2 \\
\hline 1970 (miles) & $(265.7)$ & $(52.0)$ & $(167.5)$ & $(16.2)$ & $(16.0)$ & $(425.9)$ & $(64.9)$ & $(210.9)$ & $(76.4)$ & $(84.2)$ \\
\hline Empleados, Vend. Profes. & 10.2 & 5.4 & 6.3 & 15.8 & 31.6 & 24.6 & 5.4 & 7.6 & 26.5 & 63.3 \\
\hline Agricultores & 26.7 & 43.7 & 34.7 & 11.1 & 3.1 & 19.7 & 45.4 & 32.9 & 5.9 & 2.3 \\
\hline Conductores y obreros & 18.0 & 11.8 & 16.5 & 24.1 & 17.3 & 25.8 & 15.9 & 25.5 & 36.8 & 16.8 \\
\hline Jornaleros y Serv. Pers. & 25.9 & 25.9 & 28.1 & 22.4 & 7.4 & 20.5 & 26.2 & 26.7 & 19.0 & 5.6 \\
\hline Otros & 15.6 & 11.0 & 11.9 & 22.1 & 27.4 & 7.6 & 6.4 & 6.4 & 10.2 & 7.1 \\
\hline Buscan trabajo y desocupados & 3.6 & 2.3 & 2.6 & 4.4 & 13.2 & 1.8 & 0.5 & 0.6 & 1.8 & 4.8 \\
\hline 1980 (miles) & $(301.4)$ & $(23.9)$ & $(110.6)$ & $(118.3)$ & $(68.1)$ & $(639.2)$ & $(28.8)$ & $(120.8)$ & $(180.6)$ & $(321.5)$ \\
\hline Empleados, Vend. Profes. & 14.5 & 11.7 & 11.3 & 11.7 & 27.5 & 27.2 & 11.5 & 7.8 & 13.7 & 43.7 \\
\hline Agricultores & 22.5 & 36.2 & 36.0 & 20.1 & 5.0 & 13.3 & 35.7 & 31.7 & 17.5 & 4.1 \\
\hline Conductores y obreros & 12.5 & 8.3 & 8.7 & 14.0 & 16.7 & 19.1 & 16.9 & 17.4 & 24.9 & 16.3 \\
\hline Jornaleros y Serv. Pers. & 28.0 & 28.8 & 30.0 & 31.6 & 16.6 & 18.8 & 23.9 & 30.3 & 25.1 & 11.1 \\
\hline Otros & 3.2 & --- & 0.9 & 0.2 & 0.6 & 0.8 & --- & 0.5 & --- & 1.1 \\
\hline Buscan trabajo y desocupados & 22.3 & 15.0 & 16.6 & 22.4 & 33.5 & 19.8 & 12.2 & 12.5 & 18.2 & 23.6 \\
\hline
\end{tabular}

En Panamá los altamente educados aportaban el $6 \%$ a esta categoría agregada en 1960 y hoy lo hace en un $22 \%$, pero donde el cambio es más significativo es en Chile en 
donde se pasa de un modesto $1.4 \%$ al $30 \%$ de la totalidad de los integrantes de las ocupaciones de jornaleros y de servidos personales.

\section{Consideraciones finales}

En las páginas iniciales de este texto se presentó la demanda educativa como resultado de tres aspiraciones sociales de tipo fundacional, que son la integración nacional, la movilidad social y la cultura. De ellas los datos disponibles permiten observar con exactitud lo ocurrido en la segunda variable, con alguna aproximación lo acontecido con la tercera variable y sólo por extrapolación es posible aproximarse a los cambios en la primera variable.

En materia de movilidad social la expansión de la educación como resultado de la presión popular constituyó el medio para que la juventud se formara en los niveles educativos mínimos como para afrontar los cambios de las sociedades, especialmente en las tres grandes variables definidas por la urbanización, el desarrollo de las ocupaciones no manuales y la modificación del perfil educativo de las restantes, en especial del obrero.

En ese sentido se puede decir que la educación actuó como variable de ajuste en una etapa de vertiginoso cambio estructural. Este papel permitió que la sociedad concitara expectativas muy elevadas en los resultados educativos en cuanto movilidad horizontal y vertical y que en consecuencia al sistema educativo tuviera una consideración social por encima de la calidad de los conocimientos que impartía, ya que la mera acreditación formal fue el pasaporte decisivo para la inserción en las nuevas ocupaciones que surgían con el cambio de la estructura.

Los países analizados tienen la virtud de demostrar en un caso el virtual agotamiento del cambio estructural y en el otro sumar a esto los efectos de una sucesión de políticas, en la que la primera intentó generar un proceso de movilidad social ascendente por la vía educativa y la segunda un proceso de jerarquización entre las distintas clases sociales por la vía de la reducción del amplio espectro de ocupaciones intermedias y en su etapa final por dejar la desocupación como una de las alternativas frecuentes para los jóvenes.

En ambos casos importa sí destacar que con estructuras ocupacionales progresivamente cristalizadas el papel de la educación necesariamente será otro, ya que las selecciones para los limitados puestos que se generen en las cópulas sociales serán muy estrictas y la competencia muy elevada de acuerdo con los niveles educativos de conocimientos efectivamente adquiridos, o, por el contrario, de acuerdo con métodos adscriptivos que reserven las posiciones jerárquicas para un solo grupo social.

No es posible determinar con la información disponible si las inserciones ocupacionales manuales de personas altamente educadas reflejan un circuito de origen social bajo, educación deteriorada e inserción social inferior o por el contrario, una progresiva diversificación de los niveles culturales de las categorías manuales. Si fuera el primer caso o más bien si su responsabilidad fuera exclusiva, el problema que se plantea es el de la calidad de conocimientos en aquellos establecimientos educativos que atienden al sector popular de la sociedad. Si el peso mayor estuviera en la alternativa de diferenciación cultural habría que reconsiderar cuáles son los componentes más adecuados de una formación que, como básica, tiende a ser de 10 años, para una población joven que se va a desempeñar en las más variadas ocupaciones. 
Aun suponiendo cierto deterioro en la calidad de los aprendizajes debe considerarse que la alta proporción de jóvenes con educación superior en ocupaciones manuales abre nuevas fronteras en la transformación tecnológica de la región, pero por encima de todo crea inéditas fronteras en lo cultural y en lo político.

Si la educación es una potencialidad de participar en la cultura, los viejos moldes de élites y de vasto y basto pueblo se están modificando en forma acelerada para las generaciones jóvenes. Sus demandas no pueden ser ya sólo la de la satisfacción de necesidades mínimas sino que el concepto de mínimo ha de incluir el consumo cultural.

En lo político estos cambios educativos posibilitan el establecimiento de códigos comunes y ciertamente elaborados entre la mayor parte de los jóvenes, lo que da por primera vez oportunidad de que sea real el viejo mito de la reforma universitaria en cuanto a la alianza entre obreros y estudiantes, modificada a la fecha por la de obreros e intelectuales -en el sentido de quienes no son manuales y tienen una educación apta para consumir cultura y mensajes políticos - lo que señalaría que las aspiraciones a la integración nacional, entendida necesariamente como participación, y a la cultura, comienzan a ser reales para los países más modernizados de la región.

Pero si esto es así la confrontación con los modelos de dominio político y social pasaría a tener una dimensión nueva. Educar a los jóvenes y luego volcarlos a la desocupación es actuar de partera de un movimiento social juvenil que puede ser, en la perspectiva de la crisis económica en que se desliza América Latina, el nuevo movimiento social por excelencia.

Pero aun sin las condiciones extremas de Chile es posible pensar que los mecanismos de legitimación del orden social, consistentes en apoyarse en las gratificaciones derivadas de los acelerados cambios de la estructura ocupacional y en los aún más acelerados de la educación, están llegando a su fin para algunos países de la región.

En el futuro las demandas sociales serán de otro tipo. No existiendo expectativas de alta movilidad individual ascendente, el eje de las reivindicaciones necesariamente tendría que pasar por la modificación de la distribución del ingreso de forma tal que al estándar social a que de lugar ser obrero o personal de servicio no se encuentre abrumadoramente distanciado del que obtiene un profesional, por ejemplo - Eso significa que las distancias que hoy median entre los, ingresos del $5 \%$ más rico de la sociedad y el $20 \%$ más pobre, que en algún país latinoamericano llega a ser hasta de 60 , tiendan a desplazarse hacia el perfil de los países de mejor distribución social, entre los desarrollados, donde esa distancia es de 6 veces. Esto, por supuesto, implicaría cambios en las estructuras de poder que fueron poco afectadas con la transición estructural de las últimas dos décadas. 


\section{BIBLIOGRAFIA}

AHMED, M. y P. COOMBS. Education for Rural Development. Case-Studies for Planners. ICED.

New York: Praeger, 1975.

HADDAD, W. Diviersified Secondary Currtculum Study: A Review of World Bank Experience. Washington: World Bank, 1979.

HURST, P. Implementtng Innovatory Projects: A Critical Reuiew of the Literature. Washington: World Bank, 1978.

JENKS, CHRISTOPHER, et. all. Inequality. A Reassesment of the Effect of Family and Schooling in America. New York: Harper Colophon Books, 1972.

KING, K. Education and Self-Employment, París, UNESCO, IIEP, 1978.

MEN-SER. Evaluación del Rendimiento Externo del Bachillerato Colombiano: Informe Final sobre la Cohorte de Bachilleres Egresados en el Año de 1978. Bogotá, Octubre de 1982.

PSACHAROPOULOS, G. Y C. SOUMELIS. "A quantitative analysis of the demand for higher edueducation". Higher Education. Amsterdam: Elsevier, 1979.

SCHIEFELBEIN, E. Y J. FARREL. Eight years of their lives. Through Schooling to the labor Market in Chile. Ottawa: IDRC, 1982.

VAN DE GEER, JOHN. Introduction to Multivariate Anal ysis for the Social Sciences. San Francisco W.M. Freeman and Co., 1971.

WEEKS, S. The Foster Fallacy in Educational Planning. ERURR No. 32. University of Papua New Guinea, 1978. 